\title{
Optimasi Bentuk Struktur Elemen Cangkang Pada Pondasi Terapung Menggunakan Metode Algoritma Genetik
}

\author{
Shape Optimization of Structural Shell Element in Floating Foundation Using \\ Genetic Algorithm Methode
}

\author{
Augusta Adha ${ }^{1}$, Mahadi Kurniawan ${ }^{2}$ \\ ${ }^{1,2}$ Program Studi Teknik Sipil, Fakultas Teknik, Universitas Islam Riau \\ augusta.adha@eng.uir.ac.id \\ mahadi.kurniawan@eng.uir.ac.id
}

\begin{abstract}
Abstrak
Prinsip dasar pondasi terapung adalah keseimbangan antara berat struktur atas dan total berat tanah (termasuk didalamnya air tanah) yang dipindahkan oleh konstruksi pondasi. Pondasi terapung sangat baik digunakan pada daerah dengan daya dukung tanah yang rendah dikarenakan pondasi terapung membagi gaya ke area kontak yang sangat besar sehingga seluruh area kontak tersebut hanya mengalami tegangan yang relatif kecil. Oleh karena itu, sangat penting untuk mendesain bentuk pondasi terapung yang mampu memberikan gaya apung terbesar dengan kemampuan menghasilkan tegangan yang rendah pada bidang kontak.

Paper ini membahas optimasi bentuk pelat cangkang yang digunakan pada pondasi terapung agar memiliki daya dukung yang cukup untuk menahan gaya yang ditransferkan oleh struktur atas. Metode algoritma genetik digunakan dalam proses optimasi dimana koordinat dari titik yang menyusun bentuk (shape) struktur cangkang $\left(c_{n}\right)$ dipakai sebagai desain variabel. Tegangan yang terjadi pada struktur cangkang tersebut di evaluasi dengan Analisa Elemen Hingga dengan perilaku element cangkang seperti model teory pelat Reissner-Midlin.
\end{abstract}

Kata kunci: Struktur Cangkang; Teori Reissner-Mindlin;Algoritma Genetik

\begin{abstract}
The basic principle of floating foundation is counterforce balancing between the weight of the structure and the total weight of the soil (including groundwater) which is displaced by the structure. Floating foundation is effective in areas with low soil bearing capacity because the external load is widely spread that resulting lower stress level in contact area; Hence, it is necessary to design the shape of floating structure that provide adequate uplift whilst also create lower stress level by spreading the external load to wider contact area.

This paper discusses the shape optimization of the floating foundations to have sufficient capacity to resist the force transferred by the upper structure whilst also minimize the use of material without resulting element overstress. Genetic algorithm method is used in the optimization process where the coordinates of the points that shape the shell structure $\left(c_{n}\right)$ are used as variable designs. In this study, the multivariable optimization using finite element model is investigated. The stress that occurs in the shell structure is evaluated by Finite Element Analysis with the behavior of shell elements based on Reissner-Mindlin plate theory.
\end{abstract}

Keywords: Shell Structure, Reissner-Mindlin Theory, Genetic Algorithm 


\section{PENDAHULUAN}

Struktur cangkang telah lama diterapkan pada industri bangunan karena elemen struktur cangkang memiliki karakteristik yang lebih efisien dari sisi ekonomi dan teknologi. Elemen struktur cangkang dapat memberikan kapasitas yang tinggi, sehingga dapat digunakan pada struktur dengan bentang yang sangat besar namun dengan penggunaan material yang relatif lebih sedikit dibandingkan tipe elemen struktur lain [1]. Atas dasar untuk meman-faatkan karakter elemen struktur cangkang tersebut, maka desain konstruksi bangunan dapat menjadi lebih ringan sehingga cocok untuk di aplikasikan di daerah dengan daya dukung tanah yang rendah seperti pada daerah gambut atau daerah aliran sungai. Selain itu, truktur cangkang memiliki bentuk fisik yang melengkung (curved) sehingga secara estetika sangat baik dan aerodinamis. Oleh karena itu, saat ini struktur cangkang lumrah digunakan pada fuselage pesawat, lambung kapal, dan atap bangunan dengan bentang besar.

Sebuah sistem struktur akan mengalirkan gaya-gaya yang terjadi pada struktur atas (upper structure) ke struktur bawah (sub structure) sebelum kemudian di tahan oleh tanah. Oleh karena itu, struktur bawah dalam hal ini adalah pondasi harus memiliki daya dukung yang cukup untuk menahan aliran gaya dari upper structure. Pada struktur pondasi terapung, daya dukung pondasi terapung di hasilkan dari interaksi antara area bidang kontak pondasi dengan tanah. Sehingga untuk menghasilkan daya dukung yang maksimum elemen struktur cangkang pada pondasi terapung harus disusun agar dapat menghasilkan luas bidang interaksi terbesar dengan tanah. Akan tetapi disisi lain, meningkatkan luas area pondasi terapung akan berakibat kepada penggunaan material yang lebih banyak. Peningkatan luas area tersebut juga berimbas kemungkinan terjadinya kelebihan tegangan (overstress) pada elemen struktur pondasi terapung tersebut apabila bentuk strukturnya tidak memperhatikan aliran gaya dan compactness dari penampang. Untuk mengatasi kedua problem tersebut, perlu dilakukan optimasi untuk mencari jalan tengah agar struktur dengan bentuk yang kompak dan tidak mengalami overstress dapat juga menghasilkan bidang kontak yang besar dengan tanah yang pada akhirnya akan menghasilkan struktur pondasi terapung dengan daya dukung yang cukup sesuai desain.

Permasalahan dalam optimasi secara umum dapat dikelompokkan kedalam 3 bagian yaitu geometri yang terkait dengan parameter bentuk struktur yang terkait erat dengan kekuatan dan compactness penampang struktur, mekanikal yang berhubungan dengan fungsi tujuan dan fungsi kendala dari optimasi dan matematis terkait fungsi matematis permasalahan minimisasi struktur. Paper ini memfokuskan pembahasan pada bagian pertama terkait permasalahan parameter bentuk/ geometri struktur.

Kekuatan dan kekompakan bentuk struktur pondasi terapung di hitung menggunakan metode matematis Analisa Elemen Hingga dengan menerapkan teori pelat Reissner-Mindlin [2-4] pada analisis. Untuk membentuk model geometri pelat cangkang yang akan dianalisa menggunakan Analisa Elemen 
Hingga dapat memanfaatkan dua teknik yaitu teknik model CAD (Computer-Aided Design) dan metode model meshing elemen hingga. Pada model CAD, elemen struktur dibentuk dengan menggunakan vektor seperti $B$ spline, NURBS (Non-uniform Rational B-spline) atau T-spline sebagai parameter geometry struktur $[5,6]$. Sehingga dalam proses optimasi, variabel desain yang digunakan terkait dengan nilai pembentuk karakteristik vektorvektor parameter dari elemen pelat cangkang tersebut. Pada proses optimasi, penggunaan nilai karakteristik dari vektor parameter tersebut sebagai variabel desain akan membuat domain hasil dari proses optimasi menjadi lebih kecil. Hal ini disebabkan oleh jumlah variabel desain pada metode CAD lebih sedikit dibandingkan dengan menggunakan metode meshing elemen hingga (FE-meshing). Namun demikian, proses untuk melakukan analisa elemen hingga menjadi lebih panjang karena area yang dibentuk oleh vektor parameter dari CAD harus dibentuk menjadi sebuah elemen hingga.

Lain halnya dengan model CAD, model meshing elemen hingga (FE-meshing), dimana elemen struktur menggunakan lokasi spasial dari nodal yang membentuk elemen struktur. Sehingga proses optimasi akan menggunakan lokasi spasial dari nodal tersebut sebagai variabel desain optimasi bentuk. Kelebihan dari model ini adalah kebebasan algoritma optimasi untuk menelusuri domain area hasil yang sangat luas sehingga akan didapatkan hasil optimasi yang sangat optimum. Namun demikian, sering kali bentuk dari struktur hasil optimasi tidak beraturan sehingga sulit diaplikasikan di lapangan. Untuk mengatasi hal tersebut, digunakan teknik-teknik filtering dan mesh regularization [7]. Pada penelitian ini, konsep pemodelan dengan meshing elemen (FE-meshing) diterapkan untuk membentuk elemen struktur cang-kang. Pemilihan konsep ini dikarenakan fleksibilitas model FE-meshing untuk menghasilkan produk optimasi struktur yang paling optimum. Proses optimasi dengan menggunakan model FE-meshing ini sering juga dinamakan sebagai optimasi bentuk struktur dengan variabel parameter bebas (parameter free shape optimization) [8].

Metode optimasi yang dipakai pada penelitian ini adalah metode Algoritma Genetik (AG). Alogritma Genetik adalah algoritma pencarian acak (stochastic) yang terinspirasi dari proses evolusi teori Darwin tentang "survival of the fittest"[9]. Karena sifatnya yang stochastic, metode Algoritma genetik melakukan pendekatan "pencarian acak" untuk menemukan titik solusi yang paling optimum. Selain itu, metode ini bersifat sangat umum, sehingga metode ini telah di aplikasikan pada berbagai bidang [10-15]. Pada penelitian ini 11, 13 dan 15 variabel desain digunakan untuk melihat sensitivitas desain variable tersebut terhadap hasil optimasi seperti terlihat pada Gambar 1. Dengan menggunakan para-meter optimasi yang tepat, maka dapat dihasilkan bentuk struktur cangkang yang optimum untuk menahan beban-beban yang bekerja pada sebuah pondasi terapung. Selain itu, struktur pondasi tersebut juga dapat menghasilkan tingkat stabilitas yang baik untuk daya angkat. 


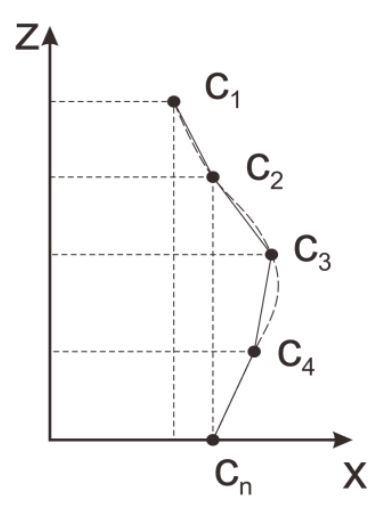

(a)

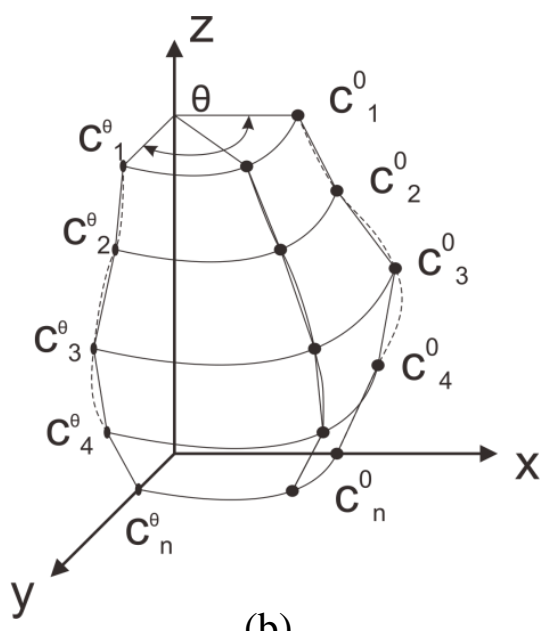

(b)

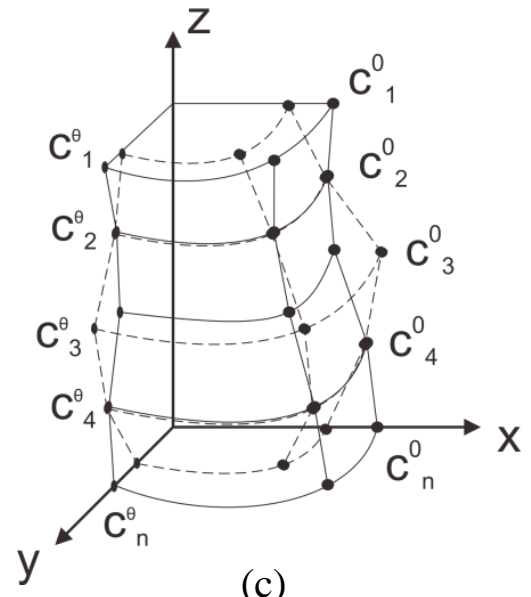

(c)

Gambar 1 " $n$ " buah variabel desain pada proses optimasi $\left(x_{n}\right)$ untuk modifikasi bentuk struktur

\section{METODE PENELITIAN}

Optimasi bentuk struktur pondasi terapung yang dimodelkan sebagai sebuah struktur cangkang dengan menggunakan metode stochastic seperti Metode algoritma genenik memerlukan proses iterasi antara beberapa kombinasi analisa yang saling berkaitan. Secara umum, proses optimasi terdiri dari 4 langkah yaitu, pemodelan geometri struktur, evaluasi mekanis dari model dengan menggunakan analisa elemen hingga (Finite Element Analysis). evaluasi nilai fitness sebuah model elemen, dan pengecekan konvergensi hasil optimasi.

Step 1. Pemodelan geometri struktur. Optimasi struktur membutuhkan parameter geometri yang baik untuk menghasilkan sebuah model yang dapat dievaluasi tingkat optimumnya. Parameter geometri tergantung dari jenis metode yang digunakan untuk membentuk model struktur, antara lain metode CAD dan
FE-meshing. Dalam paper ini, metode FE-meshing diterapkan untuk membentuk sebuah model struktur cangkang pondasi terapung. Parameter tersebut terdiri dari nodal pada elemen struktur cangkang. Pada penelitian ini variabel desain yang digunakan dibatasi pada perubahan koordinat pada sumbu x gambar 1(a). Hal ini dimaksudkan untuk mengatasi keterbatasan sumberdaya komputasi. Seperti diilustrasikan pada

Gambar 1(a) nodal - nodal pada elemen 3D dibentuk dari model 2D yang terdiri dari variabel desain $\left(x_{1}, x_{2}, \ldots x_{n}\right)$ sehingga,

$$
c_{n}\left(x_{n}, z_{n}\right) \text { dimana } \mathrm{n}=1 . . \mathrm{n}
$$

Model 3D struktur pondasi terapung seperti pada gambar 1(b) dihasilkan dari proses ekstrusi model 2D terharap rotasi polar $\theta$. Sehingga koordinat nodal yang dibentuk dari ekstrusi polar tersebut $\left(c_{n}^{\theta}\right)$ dalam sumbu Cartesian adalah,

$$
c_{n}^{\theta}\left(x_{n}^{\theta}, y_{n}^{\theta}, z_{n}^{\theta}\right)
$$


dengan,

$$
\begin{gathered}
x_{n}^{\theta}=x_{n} \cos \theta \\
y_{n}^{\theta}=x_{n} \sin \theta \\
z_{n}^{\theta}=z_{n}
\end{gathered}
$$

dimana $\mathrm{n}$ adalah jumlah variabel desain, dan $\theta$ adalah rotasi polar.

Step 2. Analisa elemen hingga (Finite Element Analysis) struktur cangkang.

Teori pelat yang sering di pakai dalam metode elemen hingga adalah teori pelat Kirchoff dan teori pelat Reissner-Mindlin [16]. Perbedaan mendasar dari kedua teori pelat ini adalah kemampuan dari kedua teori pelat tersebut untuk mengakomodasi prilaku dari pelat berdasarkan tingkat ketebalan pelat. Teori pelat Kirchoff lebih baik dalam merepresentasikan plat yang tipis (thin shell), sementara teori plat Reissner-Mindlin sangat baik untuk menggambarkan prilaku pelat tebal (thick shell). Formulasi teori plat yang digunakan untuk menggambarkan prilaku dari struktur cangkang pondasi terapung pada penelitian ini menggunakan teori pelat Reissner-Mindlin.

Asumsi dari dari teori pelat ReissnerMindlin adalah garis penampang elemen tetap lurus namun tidak harus tegak lurus terhadap bidang tengah (mid surface) dari elemen. Lebih lanjut, teori ini juga mengasumsikan bahwa tegangan normal yang terjadi pada bidang permukaan tengah pelat yang tegak lurus dengan sumbu $\mathrm{z}$ $\left(\sigma_{z}\right)$ dapat di abaikan. Sehingga dapat disederhanakan bahwa teori pelat Reissner-Mindlin merupakan kombinasi dari dua deformasi yaitu deformasi geser dan deformasi lentur. Dengan menggunakan asumsi tersebut, masing-masing nodal memiliki 3 DOF (degree of freedom) yaitu rotasi pada sumbu $\mathrm{x}$ dan $\mathrm{y}\left(\theta_{x}\right.$ dan $\theta_{y}$ ) serta translasi pada sumbu $\mathrm{z}$. Pada paper ini elemen cangkang yang digunakan pada pemodelan adalah elemen isoparameter quadrilateral seperti digambarkan sebagai berikut,

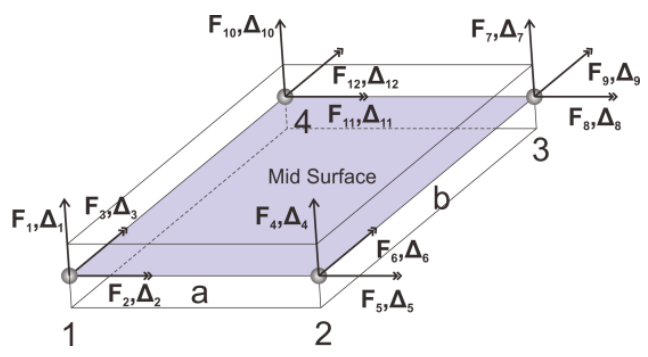

Gambar 2 Model elemen isoparameter quadrilateral

Berdasarkan asumsi dasar dari teori pelat Reissner-Mindlin, maka perpindahan nodal adalah,

$$
\begin{gathered}
u=z \cdot \theta_{x}(x, y), v=z \cdot \theta_{y}(x, y), \\
w=z(x, y)
\end{gathered}
$$

Sehingga regangan normal yang terjadi pada DOF di setiap nodal nya secara matematis dapat ditulis sebagai berikut,

$\varepsilon_{x x}=\frac{\partial \theta_{x}}{\partial x}, \varepsilon_{y y}=\frac{\partial \theta_{y}}{\partial y}, \varepsilon_{z z}=\frac{\partial \theta_{x}}{\partial y}+\frac{\partial \theta_{y}}{\partial x}$ dan regangan geser yang terjadi adalah,

$$
\begin{gathered}
\gamma_{x y}=z \cdot\left(\frac{\partial \theta_{x}}{\partial y}-\frac{\partial \theta_{y}}{\partial x}\right) \\
\gamma_{x z}=\frac{\partial w}{\partial x}+\theta_{x} \\
\gamma_{y z}=\frac{\partial w}{\partial y}+\theta_{y}
\end{gathered}
$$

Pada paper ini nodal elemen diasumsikan berada pada rotasi polar sebesar $0^{\circ}, 30^{\circ} 60^{\circ}$ dan $90^{\circ}$. Tegangan lentur dan geser yang terjadi pada elemen didasarkan pada persamaan berikut, 


$$
D_{f}=\frac{E}{1-v^{2}}\left[\begin{array}{ccc}
1 & v & 0 \\
v & 1 & 0 \\
0 & 0 & \frac{1-v}{2}
\end{array}\right]
$$

dan,

$$
\begin{gathered}
D_{c}=\left[\begin{array}{ll}
G & 0 \\
0 & G
\end{array}\right] \\
G=\frac{E}{2(1+v)}
\end{gathered}
$$

Dengan menggunakan fungsi persamaan sebagai berikut,

$$
\begin{aligned}
& N_{1}=\frac{1}{4}(1-\xi)(1-\eta) \\
& N_{2}=\frac{1}{4}(1+\xi)(1-\eta) \\
& N_{3}=\frac{1}{4}(1+\xi)(1+\eta) \\
& N_{4}=\frac{1}{4}(1-\xi)(1+\eta)
\end{aligned}
$$

Dimana $\xi$ dan $\eta$ adalah koefisien untuk elemen pelat cangkang. Maka dapat disusun sebuah matriks kekakuan elemen $[\mathrm{K}]$ untuk elemen cangkang tersebut.

$$
\begin{aligned}
K^{e}= & \frac{t^{3}}{12} \int_{-1}^{1} \int_{-1}^{1} B_{f}^{T} D_{f} B_{f}|J| d \eta d \xi \\
& +\alpha t \int_{-1}^{1} \int_{-1}^{1} B_{c}^{T} D_{c} B_{c}|J| d \eta d \xi
\end{aligned}
$$

Dimana,

$$
[J]=\left[\begin{array}{ll}
\frac{\partial x}{\partial \xi} & \frac{\partial y}{\partial \xi} \\
\frac{\partial x}{\partial \eta} & \frac{\partial y}{\partial \eta}
\end{array}\right]
$$

$$
=\left[\begin{array}{ll}
\frac{\partial}{\partial \xi} \sum_{i=1}^{4} N_{i} x_{i} & \frac{\partial}{\partial \xi} \sum_{i=1}^{4} N_{i} y_{i} \\
\frac{\partial}{\partial \eta} \sum_{i=1}^{4} N_{i} x_{i} & \frac{\partial}{\partial \eta} \sum_{i=1}^{4} N_{i} y_{i}
\end{array}\right]
$$

$$
=\left[\begin{array}{cccc}
\frac{\partial N_{1}}{\partial \xi} & \frac{\partial N_{2}}{\partial \xi} & \frac{\partial N_{3}}{\partial \xi} & \frac{\partial N_{4}}{\partial \xi} \\
\frac{\partial N_{1}}{\partial \eta} & \frac{\partial N_{2}}{\partial \eta} & \frac{\partial N_{3}}{\partial \eta} & \frac{\partial N_{4}}{\partial \eta}
\end{array}\right]\left[\begin{array}{cc}
x_{1} & y_{1} \\
x_{2} & y_{2} \\
x_{3} & y_{3} \\
x_{4} & y_{4}
\end{array}\right]
$$

Sementara untuk matriks gaya,

$$
F=\left\lfloor\begin{array}{lll}
f_{i} & m_{x i} & m_{y i}
\end{array}\right\rfloor
$$

Dimana dengan asumsi bahwa tidak terjadi momen pada nodal, maka,

$$
m_{x i}=m_{y i}=0
$$

Sehingga secara matematis dapat ditulis,

$$
f_{i}=\int_{-1}^{1} \int_{-1}^{0} N_{i} q|J| d \xi d \eta \quad i=1,2,3,4
$$

Adapun strain energi untuk pelat cangkang dengan teori reissner midlin dapat di deskipsikan dalam rumus berikut:

$$
\begin{aligned}
U= & \frac{1}{2}\left(\delta^{e}\right)^{T} \int_{V} z^{2} B_{f}^{T} D_{f} B_{f} d V \delta^{e} \\
& +\frac{\alpha}{2}\left(\delta^{e}\right)^{T} \int_{V} B_{c}^{T} D_{c} B_{c} d V \delta^{e}
\end{aligned}
$$

dengan,

$$
B_{f}=\left[\begin{array}{ccccccc}
\hline 0 & \frac{\partial N_{1}}{\partial x} & 0 & \ldots & 0 & \frac{\partial N_{4}}{\partial x} & 0 \\
0 & 0 & \frac{\partial N_{1}}{\partial y} & \ldots & 0 & 0 & \frac{\partial N_{4}}{\partial y} \\
0 & \frac{\partial N_{1}}{\partial y} & \frac{\partial N_{1}}{\partial x} & \ldots & 0 & \frac{\partial N_{4}}{\partial y} & \frac{\partial N_{4}}{\partial x}
\end{array}\right]
$$




$$
\begin{aligned}
& B_{c}=\left[\begin{array}{ccccccc}
\frac{\partial N_{1}}{\partial x} & N_{1} & 0 & \ldots & \frac{\partial N_{4}}{\partial x} & N_{4} & 0 \\
\frac{\partial N_{1}}{\partial y} & 0 & N_{1} & \ldots & \frac{\partial N_{4}}{\partial y} & 0 & N_{4}
\end{array}\right] \begin{array}{l}
\text { kondisi batas dari variabel desain LB } \\
\leq \mathrm{xn} \leq \text { UB. Karena, panjang } \\
\text { kromosom (Lbit) diatur menjadi 12, } \\
\text { maka, LB dan UB adalah 0.001 dan } \\
4,096 \text { meter masing-masing. Analisis }
\end{array} \\
& \text { maka, LB dan UB adalah } 0.001 \text { dan } \\
& \text { 4,096 meter masing-masing. Analisis } \\
& \delta^{e}=\left[\begin{array}{lllllll}
w_{1} & \theta_{x 1} & \theta_{y 1} & \ldots & w_{4} & \theta_{x 4} & \theta_{y 4}
\end{array}\right]
\end{aligned}
$$

Sementar itu, untuk proses optimasi menggunakan metode optimasi multi variable dengan kendala sebagai berikut,

$$
\left\{\begin{array}{c}
\min _{x} M s=f(x)=t \cdot A \\
\text { s.t. }\left\{\begin{array}{c}
g_{1}(x)=F-\frac{F_{u p}}{S F} \leq 0 \\
g_{2}(x)=\sigma_{v o n \text { misses }}-\sigma_{\text {all }} \leq 0 \\
L B \leq x \leq U B
\end{array}\right.
\end{array}\right.
$$

Penilaian fungsi kendala diatas dilakukan dengan prinsip berikut,

$$
g_{i}(x)\left\{\begin{array}{l}
0 \leftarrow \sigma_{i}<\sigma_{a v g} \\
\sigma_{i} \leftarrow \sigma_{i} \geq \sigma_{a v g}
\end{array}\right.
$$

Sementara fungsi penalti untuk proses optimasi menggunakan fungsi berikut,

$$
P=\sum_{i=1}^{n_{-} \text {element }}\left(M s_{i}{ }^{\alpha}+r_{1} \cdot g_{i}{ }^{2}(x)\right)
$$

dimana $\alpha=1.5$ yang bertujuan untuk menurunkan penalti terhadap struktur yang mempunyai masa struktur yang rendah dan dimana Ms adalah massa struktur. Fungsi fitness struktur dirumuskan dengan fungsi berikut.

$$
\text { fitness }=\frac{r_{2}}{P}
$$

\section{HASIL ANALISA DAN PEMBAHASAN}

Secara umum langkah-langkah tersebut meliputi pembuatan generasi awal, proses kawin silang, mutasi, dan seleksi. Generasi awal (P0) dihasilkan secara acak berdasarkan
Proses iterasi secara bertahap meningkatkan fitness individu baru dengan mengubah variabel desain. Setelah menyempurnakan proses optimasi, tingkat crossover (pco) dan laju mutasi $(\mathrm{pm})$ ditetapkan masingmasing sebagai 0.95 dan 0.05 . Individu yang paling cocok dalam generasi pertama digambarkan pada Gambar 6(a) dengan nilai kebugaran 1,127 dan ditingkatkan melalui iterasi ke generasi 60 di mana individu yang paling sesuai digambarkan dalam Gambar 6(b) dengan nilai kebugaran 150,467.

Berdasarkan model tersebut, didapatkan struktur optimum yang paling baik untuk kendala yang telah dijelaskan sebelumnya dapat digambarkan sebagai berikut,

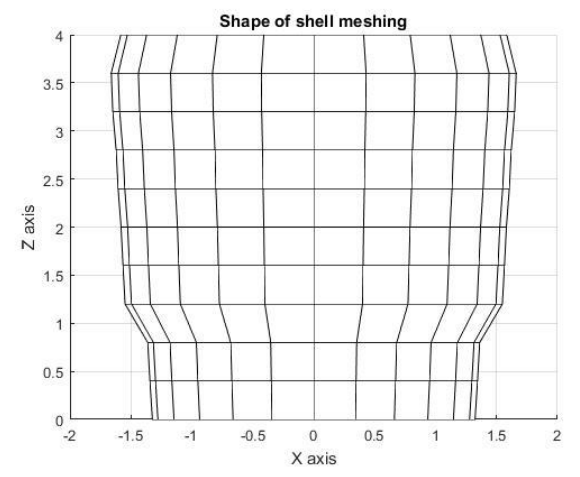

Gambar 3 Hasil optimasi struktur pada iterasi ke-300

Proses iterasi untuk mencapai generasi ke 300 tersebut dapat digambarkan pada gambar 4 . 

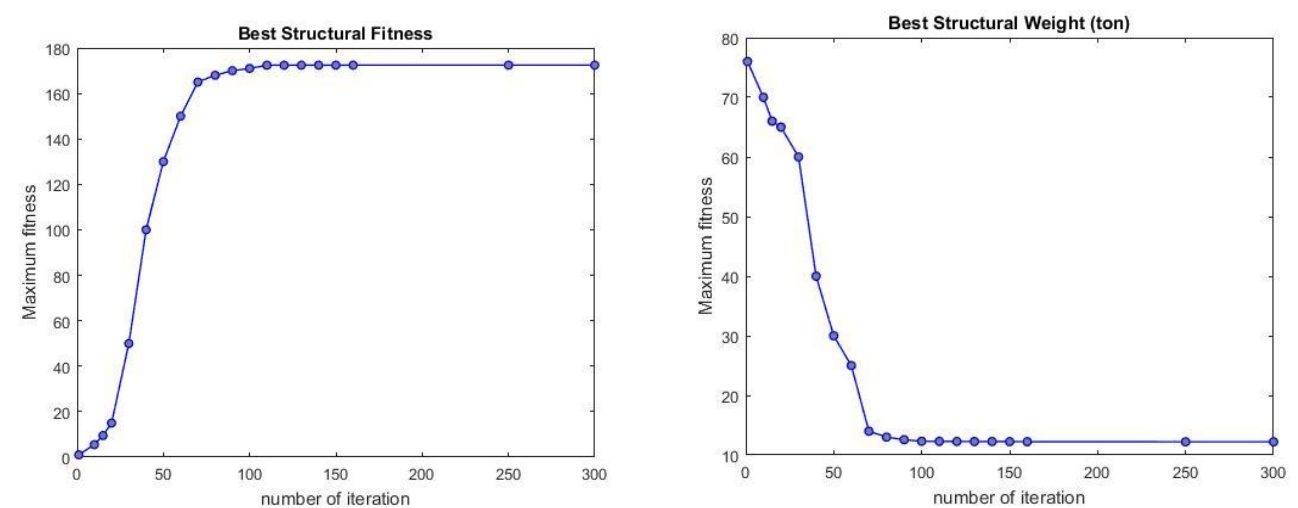

Gambar 4 Fitness dan volume struktur pada setiap iterasi

Tabel 1 Nilai variable desain x untuk menentukan bentuk dari struktur

\begin{tabular}{cccccccccccc}
\hline $\begin{array}{c}\text { Design } \\
\text { Variable }\end{array}$ & $x_{1}$ & $x_{2}$ & $x_{3}$ & $x_{4}$ & $x_{5}$ & $x_{6}$ & $x_{7}$ & $x_{8}$ & $x_{9}$ & $x_{10}$ & $x_{11}$ \\
\hline $\mathrm{x}(\mathrm{m})$ & 1.323 & 1.344 & 1.362 & 1.548 & 1.565 & 1.581 & 1.605 & 1.621 & 1.649 & 1.661 & 1.583 \\
\hline
\end{tabular}

Berdasarkan Gambar 4 dapat dilihat bahwa semakin meningkatnya iterasi, fitness struktur semakin baik yang ditandai dengan semakin menurunnya volume material struktur yang dipakai sehingga massa struktur juga menjadi semakin turun.
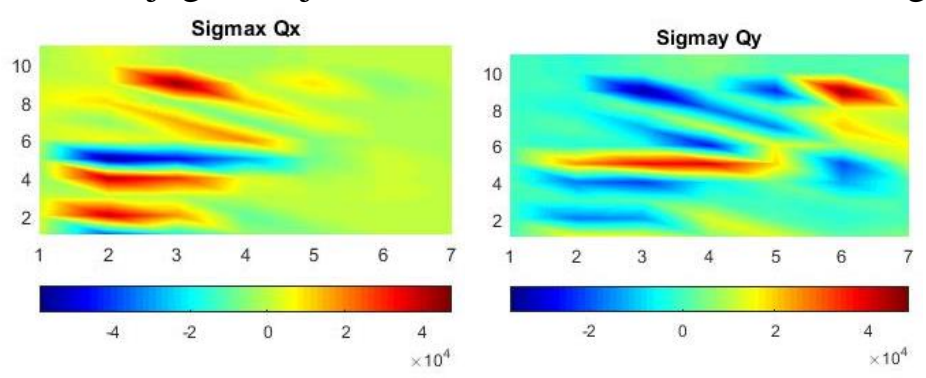

Proses optimasi juga menggunakan kendala tegangan struktur. Adapun tegangan yang terjadi pada struktur yang telah mengalami proses optimasi dapat di gambarkan pada skema tegangan berikut,

Gambar 5 Tegangan normal elemen di layer -0.1 m dari bidang netral
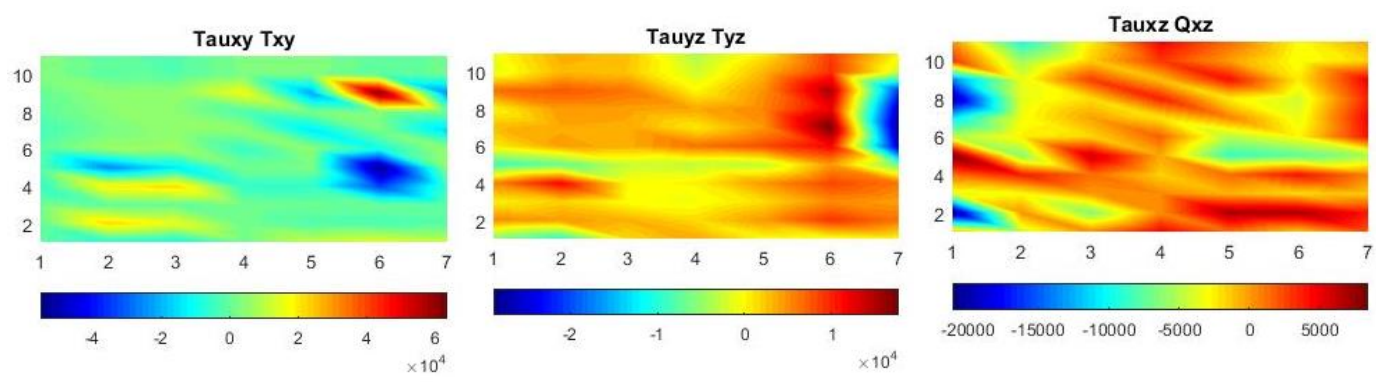

Gambar 6 Tegangan geser elemen di layer -0.1 dari bidang netral 

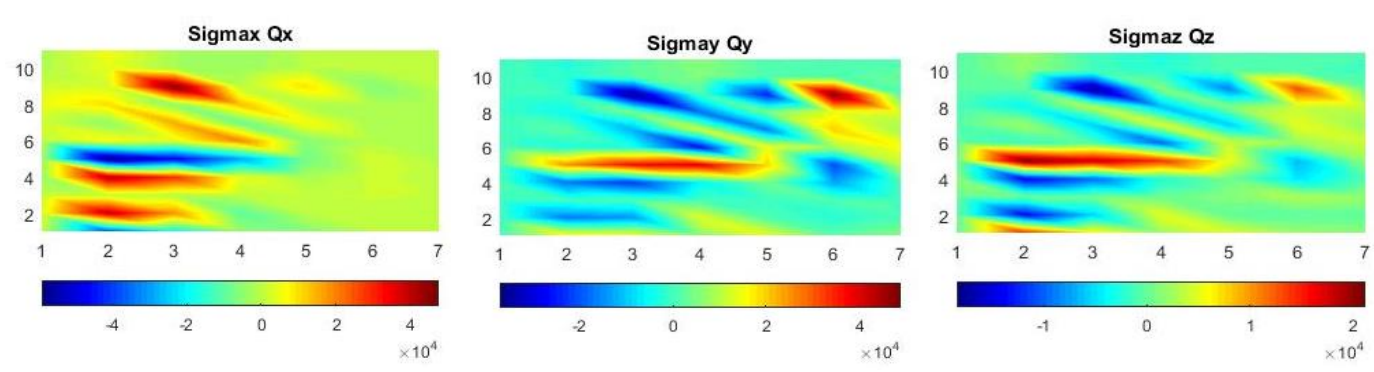

Gambar 7 Tegangan normal pada layer 0.1 dari bidang netral
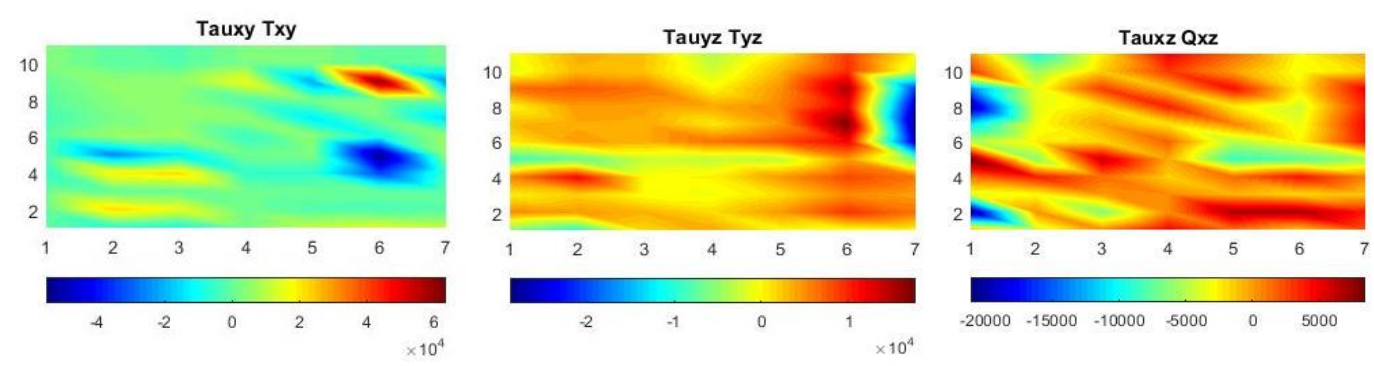

Gambar 8 Tegangan geser pada layer 0.1 dari bidang netral

Berdasarkan hasil analisa, didapatkan bahwa tegangan normal $\left(\sigma_{x}, \sigma_{y}\right.$, dan $\left.\sigma_{z}\right)$ maksimum yang terjadi pada elemen pelat cangkang dari pondasi terapung adalah 47.68, 48.98 and 21.16 Mpa. Sementara, tegangan geser $\left(\gamma_{\mathrm{xy}}, \gamma_{\mathrm{yz}}\right.$, and $\left.\gamma_{\mathrm{xz}}\right)$ maksimum yang terjadi pada bidang elemen pelat cangkang hasil dari optimasi adalah 6.36, 17.51, dan 8.44 Mpa.

Seperti yang dibahas sebelumnya, struktur di optimasi dengan menggunakan kendala tegangan allowable material struktur sebesar 50 Mpa untuk tegangan normal allowable dan $35 \%$ dari tegangan normal allowable untuk batas tegangan geser allowable. Penggunaan reduksi $35 \%$ ini mengacu kepada peraturan ACI 318 yang mengaturan reduksi kekuatan material yang mengalami tarik.

Tegangan yang terjadi pada elemen cangkang untuk struktur pondasi terapung yang telah mengalami optimasi struktur memperlihatkan hasil yang memenuhi batas kendala tegangan. Sementara hasil optimasi untuk variable desain koordinat $\mathrm{x}$ yang merupakan fungsi bentuk dari struktur pondasi terapung memperlihatkan hasil yang sesuai dengan batasan kendala $0.001 \leq \mathrm{x}_{\mathrm{n}} \leq$ 4,096 m seperti yang di tampilkan pada Tabel 1.

\section{KESIMPULAN}

Teknik optimasi yang di gunakan dalam penelitian ini telah dapat menghasilkan sebuah model struktur pondasi terapung yang memenuhi semua kendala yang diberikan yaitu tingkat faktor keamanan, tingkat tegangan dan dimensi. Namun demikian, perlu dilakukan percobaan yang terukur untuk mengkonfirmasi hasil analisa dari model numerik yang telah dilakukan sebelumnya. Pembebanan yang diberikan pada struktur ini baru merupakan pembebanan statik searah, sementara untuk aplikasi di lapangan, pembebanan yang terjadi seringkali adalah pembebanan dinamik dan multi arah. Sehingga kedepannya, 
penelitian selanjutnya harus

melakukan pendalaman terhadap kondisi pembebanan tersebut.

Optimasi struktur yang di teliti pada penelitian ini melakukan penyederhanaan model struktur pada analisa elemen hingga (FEA). Namun, jika struktur yang diberikan lebih rumit, nampaknya proses iterasi akan membutuhkan waktu komputasi yang lebih lama. Oleh karena itu, di masa depan, bidang ini harus dieksplorasi lebih dalam untuk mendapatkan konvergensi yang lebih cepat dengan sumber daya komputasi yang lebih sedikit. Selanjutnya, teknik-teknik baru pada NURBS telah dikembangkan dengan cepat untuk menghasilkan model yang lebih dinamis. Di masa depan, metode NURBS dapat diterapkan untuk membentuk model struktur. Teknik ini akan membuat optimisasi menjadi sangat mudah beradaptasi dengan paket analisis struktural yang ada di pasar.

\section{DAFTAR PUSTAKA}

[1] E. Ramm, K.-U. Bletzinger, and R. Reitinger, "Shape optimization of shell structures," Revue Européenne des Éléments Finis, vol. 2, no. 3, pp. 377398, 1993/01/01 1993.

[2] D. J. Benson, Y. Bazilevs, M. C. Hsu, and T. J. R. Hughes, "Isogeometric shell analysis: The Reissner-Mindlin shell," Computer Methods in Applied Mechanics and Engineering, vol. 199, no. 58, pp. 276-289, 2010.
[3] M. Bischoff, W. A. Wall, K.U. Bletzinger, and E. Ramm, "Models and finite elements for thin-walled structures," in Encyclopedia of Computational Mechanics, Solids Structures and Coupled Problems, vol. 2, E. Stein, R. D. Borst, and T. J. R. Hughes, Eds.: Wiley, 2004.

[4] S. Cen and Y. Shang, "Developments of MindlinReissner Plate Elements," Mathematical Problems in Engineering, vol. 2015, pp. 112, 2015.

[5] K.-U. Bletzinger, S. Kimmich, and E. Ramm, "Efficient modeling in shape optimal design," Computing Systems in Engineering, vol. 2, no. 5/6, pp. 483-495, 1991.

[6] E. Sandgren and R. L. West, "Shape Optimization of Cam Profiles Using a B-Spline Representation," Journal of Mechanisms, Transmissions, and Automation in Design, vol. 111, pp. 195-201, 1989.

[7] K.-U. Bletzinger, R. Wüchner, F. Daoud, and N. Camprubí, "Computational methods for form finding and optimization of shells and membranes," Computer Methods in Applied Mechanics and Engineering, vol. 194 , no. $30-33$, pp. 3438 3452, 2005.

[8] H. Masching and K.-U. Bletzinger, "Parameter free structural optimization applied to the shape optimization of smart structures," Finite Elements in Analysis and Design, vol. 
111, pp. 33-45, 2016/04/01/ 2016.

[9] D. Goldberg, Genetic Algorithms In Search, Optimization \& Machine Learning. The University of Alabama: Addison-Wesley Publishing Co., 1989.

[10] A. Ramadan, K. Yousef, M. Said, and M. H. Mohamed, "Shape optimization and experimental validation of a drag vertical axis wind turbine," Energy, vol. 151, pp. 839-853, 2018/05/15/ 2018.

[11] C. M. Chan, H. L. Bai, and D. Q. He, "Blade shape optimization of the Savonius wind turbine using a genetic algorithm," Applied Energy, vol. 213, pp. 148-157, 2018/03/01/ 2018.

[12] E. Kita and H. Tanie, "Shape optimization of continuum structures by genetic algorithm and boundary element method," Engineering Analysis with Boundary Elements, vol. 19, no. 2, pp. 129-136, 1997/03/01/ 1997.

[13] H. Assimi, A. Jamali, and N. Nariman-zadeh, "Sizing and topology optimization of truss structures using genetic programming," Swarm and Evolutionary Computation, vol. 37, pp. 90-103, 2017.

[14] A. Adha, "Optimasi Bentuk Struktur dan Penampang pada Struktur Rangka Baja Terhadap Kendala Kehandalan Material Struktur dengan Menggunakan Metode Algoritma Genetik," pp. 100-107, 2017.
[15] X. Liu, W.-J. Yi, Q. S. Li, and P.-S. Shen, "Genetic evolutionary structural optimization," Journal of Constructional Steel Research, vol. 64, no. 3, pp. 305-311, 2008.

[16] E. Reissner, "On the theory of transverse bending of elastic plates," International Journal of Solids and Structures, vol. 12, no. 8, pp. 545-554, 1976/01/01/ 1976.

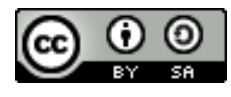

This is an open access article which means that all content is freely available without charge to the user or his/her institution. Jurnal Saintis allows the author(s) to hold the copyright without restriction. The copyright in the text of individual articles (including research articles, opinion articles, and abstracts) is the property of their respective authors distributed under the terms of the Creative Commons Attribution-ShareAlike 4.0 International License (https://creativecommons.org/licenses/bysa/4.0/] which permits unrestricted use, distribution, and reproduction in any medium. Users are allowed to read, download, copy, distribute, search, or link to full-text articles in this journal without asking by giving appropriate credit, provide a link to the license, and indicate if changes were made. 